\title{
THE PEP-II ABORT KICKER SYSTEM
}

\author{
J. de Lamare, A. Donaldson, A. Kulikov, J. Lipari \\ Stanford Linear Accelerator Center, Stanford University, Stanford CA 94309
}

\begin{abstract}
The PEP-II project has two storage rings. The HER (High Energy Ring) has up to $1.48 \mathrm{~A}$ of electron beam at $9 \mathrm{GeV}$, and the LER (Low Energy Ring) has up to $2.14 \mathrm{~A}$ of positron beam at $3.1 \mathrm{GeV}$. To protect the HER and LER beam lines in the event of a ring component failure, each ring has an abort kicker system which directs the beam into a dump when a failure is detected. Due to the high current of the beams, the beam kick is tapered from $100 \%$ to $80 \%$ in 7.33 uS (the beam transit time around the time). This taper distributes the energy evenly across the window which separates the ring from the beam dump such that the window is not damaged. The abort kicker trigger is synchronized with the ion clearing gap of the beam allowing for the kicker field to rise from $0-80 \%$ in $370 \mathrm{nS}$. This report discusses the design of the system controls, interlocks, power supplies, and modulator.
\end{abstract}

\section{DISCLAIMER}

\begin{abstract}
This report was prepared as an account of work sponsored by an agency of the United States Government. Neither the United States Government nor any agency thereof, nor any of their employees, makes any warranty, express or implied, or assumes any legal liability or responsibility for the accuracy, completeness, or usefulness of any information, apparatus, product, or process disclosed, or represents that its use would not infringe privately owned rights. Reference herein to any specific commercial product, process, or service by trade name, trademark, manufacturer, or otherwise does not necessarily constitute or imply its endorsement, recommendation, or favoring by the United States Government or any agency thereof. The views and opinions of authors expressed herein do not necessarily state or reflect those of the United States Government or any agency thereof.
\end{abstract}

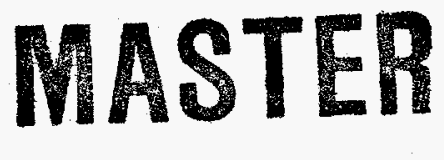

Submitted to 1997 Particle Accelerator Conference Proceedings

DISTRIBUTION OF THIS DOCUMENT IS UNLIMITED 


\title{
THE PEP-II ABORT KICKER SYSTEM*
}

\author{
J. de Lamare, A. Donaldson, A. Kulikov, J. Lipari \\ Stanford Linear Accelerator Center
}

\section{Abstract}

The PEP-II project has two storage rings. The HER (High Energy Ring) has up to $1.48 \mathrm{~A}$ of electron beam at 9 $\mathrm{GeV}$, and the LER (Low Energy Ring) has up to $2.14 \mathrm{~A}$ of positron beam at $3.1 \mathrm{GeV}$. To protect the HER and LER beam lines in the event of a ring component failure, each ring has an abort kicker system which directs the beam into a dump when a failure is detected. Due to the high current of the beams, the beam kick is tapered from $100 \%$ to $80 \%$ in $7.33 \mu \mathrm{S}$ (the beam transit time around the ring). This taper distributes the energy evenly across the window which separates the ring from the beam dump such that the window is not damaged. The abort kicker trigger is synchronized with the ion clearing gap of the beam allowing for the kicker field to rise from $0-80 \%$ in $370 \mathrm{nS}$. This report discusses the design of the system controls, interlocks, power supplies, and modulator.

\section{SYSTEM SPECTIFICATIONS}

The PEP-II beam abort kicker system is designed to divert the stored beam of the HER and LER rings into a beam dump in the event of beam based trigger or a equipment failure trigger [1]. The HER and LER abort systems operate independantly, and their operating parameters are listed in Table 1 . The rings will be operated 274 days per calendar year with scheduled maintenance 2 days per month. It is anticipated that the rings will need full refilling 3 times per day due to a failure in one of the ring's subsystems [2]; meaning, the abort system typically could be triggered 3 times per day.

\begin{tabular}{|c|c|c|}
\hline & $\begin{array}{l}\text { HER } \\
\text { (at } 9 \mathrm{GeV} \text { ) }\end{array}$ & $\begin{array}{l}\text { LER } \\
\text { (at } 3.1 \mathrm{GeV} \text { ) }\end{array}$ \\
\hline Max. Bend Angle & $1.7 \mathrm{~m}-\mathrm{rad}$ & $2.1 \mathrm{~m}-\mathrm{rad}$ \\
\hline Magnetic Field & $600 \mathrm{G}$ & $394.5 \mathrm{G}$ \\
\hline Kick Direction & Down & Down \\
\hline $\begin{array}{l}\text { Magnet Current Amplitude } \\
\text { (without overshoot) }\end{array}$ & $4800 \mathrm{~A}$ & $3156 \mathrm{~A}$ \\
\hline Magnet Current Risetime & 370ns Max. & 370ns Max. \\
\hline $\begin{array}{l}\text { Magnet Current Droop } \\
\text { (in } 7.33 \mu \mathrm{s} \text { ) }\end{array}$ & $100 \%-80 \%$ & $100 \%-80 \%$ \\
\hline Max. Pulse Rep. Frequency & $0.5 \mathrm{~Hz}$ & $0.5 \mathrm{~Hz}$ \\
\hline Typical Pulse Rep. Time & $8 \mathrm{hr}$. & $8 \mathrm{hr}$. \\
\hline
\end{tabular}

Table: 1 Abort Kicker Operating Parameters
The beam abort system must be reliable to insure that the beam won't drill a hole through a vacuum vessel in the event of a ring failure. Therefore, there is redundancy in key system components--particularly triggers. Also, the system is self triggering in the event of a power loss, disconnected input trigger cable, or detected non-critical internal fault. Though only one abort system is needed to extract the beam, a second system is planned in each ring which is triggered in the event of a detected fault of the first system, some $7.33 \mu$ s delayed or one revolution of the beam from the first kicker [3].

\section{SYSTEM COMPONENTS}

The abort kicker subsystems are: Controls and Interlocks, Modulator Ancillary Circuitry, Modulator, and Magnet.

\subsection{Controls and Interlocks}

The system control hardware consists of Camac modules which are controlled by micro-controllers which in turn are controlled by a mainframe computer. The various Camac modules include: an Isolated Digital Output Module (IDOM) for command functions, an Isolated Digital Input Module (IDIM) to provide status information, a Smart Analog Module (SAM) for recording analog readbacks, a Simple Timing Buffer (STB) for command triggering, and a Beam Abort Trigger System (BATS) for emergency triggering. There is also an Abort Kicker Modulator Controller which is a 19" rack mounted chassis that acts as the interface between the Camac controls and the Modulator with its ancillary cicuitry. The controller is discussed in more detail below.

\subsection{Modulator Ancillary Circuitry}

The Modulator Ancillary Circuitry provides the power and the triggering necessary for modulator operation. There are two grid drivers, modified BIRA SCR Thyratron Driver 730-788, which are redundant in function. They provide the thyratron grid 2 pulse which initiates current in the magnet. Redundant drivers are necessary to insure that the system is still functional in the event of a malfunction of one driver. A Thyratron Keep Alive/Bias Power Supply chassis generates -130 VDC for the grid 2 bias, and the $100 \mathrm{~mA}$ of keep alive current for grid 1 of all thyratrons within the modulator. The Thyratron Heater/Reservoir Power Supply is powered by a ferroresonant transformer which stabilizes the AC voltage. This chassis provides adjustable $A C$ power for the modulator thyratrons, a time-

\footnotetext{
- Work supported by the Department of Energy under contract No. DE-AC03-76SF00515
} 
out interlock to allow thyratron heating on startup, and sends voltage and current readbacks to the control system. A Low Voltage Power Supply (LVPS), Glassman Series ER 0-3kVDC, charges one of the modulator's pulse capacitors. It is named the LVPS only because the High Voltage Power Supply (HVPS), Glassman Series LT I $^{-}$ $30 \mathrm{kVDC}$, generates a considerably higher voltage. The HVPS also charges a pulse capacitor in the modulator.

\subsection{Modulator}

The modulator generates the high current pulse to the magnet. The circuit design is discussed in more detail later. The modulator cicuitry is housed in a $53 \mathrm{~cm} \times$ $54.5 \mathrm{~cm} \times 56 \mathrm{~cm}$ box which is located directly under the abort kicker magnet (Fig. 1). The magnet connections are made with $5 \mathrm{~cm}$ wide aluminum bus, approximately $20 \mathrm{~cm}$ long, and spaced $3.8 \mathrm{~cm}$ apart. The modulator is air cooled and uses an air filter to limit the dust intake. The ambient air temperature of the ring tunnel is expected to be $40^{\circ} \mathrm{C}$, thus the modulator components are rated appropriately.

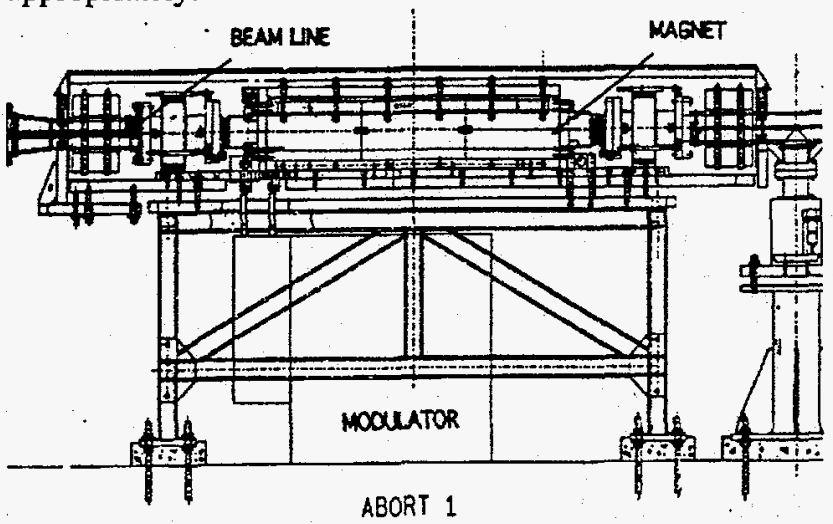

Figure: 1 Abort kicker magnet and modulator assembly

\subsection{Magnet}

The magnet is a single turn, H-type magnet made from blocks of Ceramic Magnetics CMD5005 ferrite. The HER magnet ferrite is $0.85 \mathrm{~m}$ and the LER magnet ferrite is $0.55 \mathrm{~m}$ in length. For a detailed description of the magnet design see Reference 4.

\section{ABORT KICKER CONTROLLER}

\subsection{Controls}

The abort kicker system was intentionally given a minimum number of controls such that it will not inadvertantly be manipulated. The system may be remotely turned on, turned off, reset, and switched between command trigger mode with emergency trigger to emergency trigger only mode. What the system lacks in control, it more than makes up for in diagnostics. There are a number of status bits reporting system functionality. Particularly important are the trigger statuses. The trigger sequence from the redundant BATS and Grid Driver triggers to the magnet voltage are all monitored. These diagnostics are useful to determine whether a trigger module needs repair or when self triggering occurs.

The analog readback data is stored in history buffers. These include: thyratron heater and reservior current, thyratron keep alive current, thyratron bias voltage, pulse capacitor voltages, and magnet current. Because the modulator is seldom triggered, the anaolg magnet current pulse is read by a sample and hold circuit, converted to digital, and then back to analog for monitoring by a SAM. This method eliminates the droop of a sample and hold circuit. A running history of all analog readbacks is recorded in the control system main frame computer.

\subsection{Interlocks}

The system is designed such that it is self protecting for most failures. In the event of a power loss or a failure of the modulator or its ancillary circuitry, the modulator is triggered by the BATS. The controller sends two statuses to the BATS-System O.K. and System Failing. If the modulator is O.K., then it is triggerable by a command trigger. If the status is not O.K., then the system is not ready and cannot be triggered. When the system is failing, then the system is triggered by the BATS. A list of the interlocks and the system status is given in Table 2. All of the interlocks are inhibited when the thyratron heater interlock is timing out and when a trigger command is detected.

\begin{tabular}{|c|c|}
\hline Description & $\begin{array}{l}\text { System } \\
\text { Status }\end{array}$ \\
\hline $\begin{array}{l}\text { HV Fail High }(\mathrm{V}>102 \%) \\
\text { HV OK } \\
\text { HV Falling }(0>\text { Slope } \geq-1 \% / \mathrm{ms}) \\
\text { HV Fail Low }(\mathrm{V}<98 \%)\end{array}$ & $\begin{array}{l}\text { Not Ready } \\
\text { Trigger Ready } \\
\text { Failing } \\
\text { Not Ready }\end{array}$ \\
\hline $\begin{array}{l}\text { LV Fail High }(V>102 \%) \\
\text { LV OK } \\
\text { LV Falling }(0>\text { Slope } \geq-1 \% / \mathrm{ms}) \\
\text { LV Fail Low }(\mathrm{V}<98 \%)\end{array}$ & $\begin{array}{l}\text { Not Ready } \\
\text { Trigger Ready } \\
\text { Failing } \\
\text { Not Ready }\end{array}$ \\
\hline $\begin{array}{l}\text { HV Keep Alive Current High } \\
\text { HV Keep Alive Current OK } \\
\text { HV Keep Alive Current Low }\end{array}$ & $\begin{array}{l}\text { Failing } \\
\text { Trigger Ready } \\
\text { Failing }\end{array}$ \\
\hline $\begin{array}{l}\text { LV1 Keep Alive Current High } \\
\text { LV1 Keep Alive Current OK } \\
\text { LV1 Keep Alive Current Low }\end{array}$ & $\begin{array}{l}\text { Failing } \\
\text { Trigger Ready } \\
\text { Failing }\end{array}$ \\
\hline $\begin{array}{l}\text { LV2 Keep Alive Current High } \\
\text { LV2 Keep Alive Current OK } \\
\text { LV2 Keep Alive Current Low }\end{array}$ & $\begin{array}{c}\text { Failing } \\
\text { Trigger Ready } \\
\text { Failing } \\
\end{array}$ \\
\hline $\begin{array}{l}\text { HV Bias Voltage Low } \\
\text { HV Bias Voltage OK }\end{array}$ & $\begin{array}{c}\text { Failing } \\
\text { Trigger Ready }\end{array}$ \\
\hline $\begin{array}{l}\text { LV Bias Voltage Low } \\
\text { LV Bias Voltage OK }\end{array}$ & $\begin{array}{l}\text { Failing } \\
\text { Trigger Ready }\end{array}$ \\
\hline $\begin{array}{l}\text { HV Htr/Res. Current High } \\
\text { HV Htr.Res. Current OK } \\
\text { HV Htr.Res. Current Low }\end{array}$ & $\begin{array}{c}\text { Failing } \\
\text { Trigger Ready } \\
\text { Failing }\end{array}$ \\
\hline $\begin{array}{l}\text { LV Htr./Res. Current High } \\
\text { LV Htr./Res. Current OK } \\
\text { LV Htr./Res. Current Low }\end{array}$ & $\begin{array}{c}\text { Failing } \\
\text { Trigger Ready } \\
\text { Failing }\end{array}$ \\
\hline $\begin{array}{l}\text { Heater Current Time-Out } \\
\text { Heater Current Time-Out OK }\end{array}$ & $\begin{array}{l}\text { Not Ready } \\
\text { Trigger Ready }\end{array}$ \\
\hline $\begin{array}{l}\text { ACFail } \\
\text { AC OK }\end{array}$ & $\begin{array}{c}\text { Failing } \\
\text { Trigger Ready }\end{array}$ \\
\hline $\begin{array}{l}\text { Rack Over-Temperature } \\
\text { Rack Temperature OK }\end{array}$ & $\begin{array}{c}\text { Failing } \\
\text { Trigger Ready }\end{array}$ \\
\hline $\begin{array}{l}\text { Grid Driver Failure } \\
\text { Grid Drivers OK }\end{array}$ & $\begin{array}{c}\text { Not Ready } \\
\text { Trigger Ready }\end{array}$ \\
\hline
\end{tabular}

Table: 2 Abort Kicker Interlocks and their system status. 


\section{ABORT KICKER MODULATOR}

The modulator is made up of three CX1622 thyratrons, two pulse capacitors, a damping resistor, and many other supporting components. Figure 2 shows the simplified modulator circuit. Because of the shape of the pulse, the circ it design is such that it has two parts: a high voltage part and a low voltage part. The high voltage part is made up of one CX1622 thyratron and a $0.15 \mu f, 50 \mathrm{kV}$ low inductance pulse capacitor. The capacitor charges through the magnet, and likewise discharges through the magnet when the thyratron is triggered. The resulting pulse generates a voltage on the magnet of $-25 \mathrm{kV}$.

The low voltage part of the circuit consists of two parallel CX1622R thyratrons, a $100 \mu \mathrm{f}, 4 \mathrm{kV}$ low inductance pulse capacitor, and a $0.2 \Omega$ damping resistor made from 50 parallel $2 \mathrm{~W}$ carbon composition resistors. Each thyratron is supported in a slotted cylindrical housing which acts as the current return path for low inductance. All of the thyratron cathodes are grounded at a common point. Because stray inductance in the low voltage circuit contribute to the current overshoot, the inductance of all circuit connections is minimized.

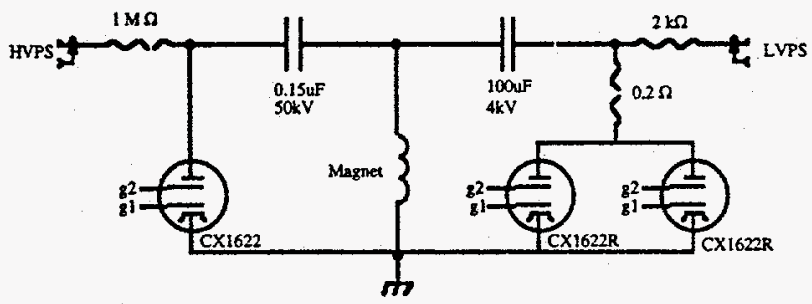

Figure: 2 Simplified Modulator Schematic

As the high voltage thyratron is triggered by the redundant grid drivers, the voltage at the magnet and the low voltage circuit goes to $-25 \mathrm{kV}$, and a half sine current pulse is initiated in the magnet, with the high voltage circuit capacitance and inductance determining the current risetime. The low voltage thyratrons are triggered in parallel with a pulse formed by a current transformer positioned on the connection from the modulator to the magnet. Therefore, the low voltage thyratrons will always be triggered when the high voltage thyratron conducts whether from a command trigger or a self trigger.

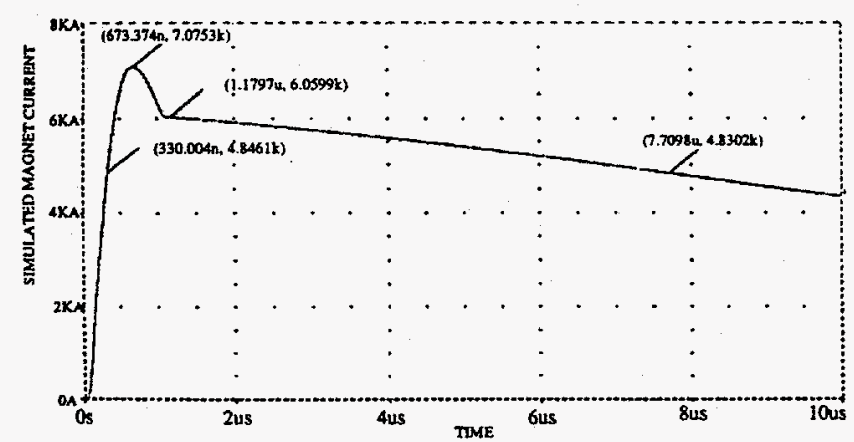

Figure: 3 Simulated Magnet Current Waveform
As the magnet voltage swings through zero, the low voltage thyratrons become positively biased, and conduction begins. Initially, the magnet supplies current through the low voltage circuit up to a point where the $R$ $C$ network of the circuit gives the waveshape an exponentially decaying tail.

The circuit was modeled with a circuit simulation program. The model included the stray inductances of the capacitors and thyratrons, the inductance of the magnet connection, and a model of the magnet as given in Reference 4. Using the model, the first $10 \mu$ s of magnet pulse is shown in Figure 3. The overshoot results from the stray inductance in the low voltage circuit which limits the circuit's current risetime and allows for the high voltage circuit current to swing past its peak.

\section{CONCLUSIONS}

The modulator has been completed and tested into the magnet. Figure 4 shows the test results. The model is in good agreement with the test results. The controller isn't yet completed, so the total system has not yet been tested. Within the year the total system will be field tested with beam.

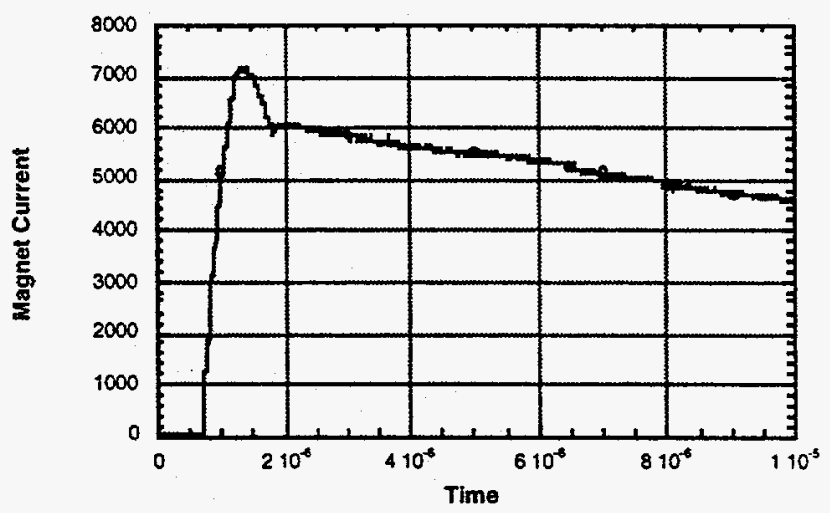

Figure: 4 Abort kicker current test results.

\section{ACKNOWLEDGEMENTS}

We want to thank Piotr Blum for his efforts in the assembly of the modulator, the design and fabrication of many of its parts, and for the assembly of many of the subsystems. We also want to thank Joe Olszewski for his dedication and suppor on this project.

\section{REFERENCES}

[1] W. Barry, et. al.: 'Criteria for Beam Abort in PEP-II', SLAC-PEP-II-AP-NOTE-9-94, June 1994. 2pp.

[2] J. Dorfan, M. Zisman: 'PEP-II Operational Efficiency: Assumptions and Guidelines--Part I', SLAC-PEP-II-TECHNICAL-NOTE-18, Mar 1993. 2pp.

[3] A. Kulikov, et. al.: 'PEP-II Abort Systm Specifications', SLAC-PEP-II-TECHNICAL-NOTE61, Oct 1994. 13pp.

[4] G. C. Pappas, et. al.: 'The PEP-II Injection Kicker System', PAC97 


\section{DISCLAMIER}

Portions of this document may be illegible in electronic image products. Images are produced from the best available original document. 